\title{
MATURAÇÃO DE UVAS MOSCATO GIALLO SOB CULTIVO PROTEGIDO ${ }^{1}$
}

\author{
GERALDO CHAVARRIA², HENRIQUE PESSOA DOS SANTOS ${ }^{3}$, MAURO CELSO ZANUS ${ }^{4}$, \\ GILMAR ARDUÍNO BETTIO MARODIN ${ }^{5}$, MÔNICA ZUCOLLOTO CHALAÇA ${ }^{6}$, CRISTIANO ZORZAN ${ }^{7}$
}

RESUMO - O cultivo protegido de videiras é um sistema de cultivo recente, podendo modificar o microclima no entorno da planta e as condições de maturação da uva. Desta forma, este trabalho objetivou avaliar a influência da cobertura plástica sobre a maturação de uvas 'Moscato Giallo'. O experimento foi realizado nos ciclos de 2005/06 e 2006/07, em vinhedo com cobertura plástica impermeável (160 $\mu \mathrm{m})$, deixando-se cinco fileiras sem cobertura (controle). Foram realizadas coletas semanais de três repetições de 100 bagas de cada área (coberta e controle). Nestas bagas, foram medidos a massa, o diâmetro e a composição do mosto: $\mathrm{pH}$, sólidos solúveis, acidez total, ácidos tartárico e málico. No momento da colheita, também foram caracterizados os mostos das uvas cobertas e descobertas ( ${ }^{\circ}$ Brix, açúcares redutores, densidade, acidez total, ácidos tartárico e málico, pH e rendimento). A despeito de uma importante interferência no microclima do dossel vegetativo e cachos, a cobertura plástica influencia na maturação das uvas. Em função da diminuição da radiação fotossinteticamente ativa, que retarda o acúmulo de açúcares, as uvas sob cobertura plástica devem ser colhidas posteriormente àquelas do cultivo convencional.

Termos para indexação: plasticultura, microclima, amadurecimento, manejo.

\section{GRAPEVINE MATURATION OF MOSCATO GIALLO UNDER PLASTIC COVER}

\begin{abstract}
Plastic overhead cover (POC) is a recent viticulture practice in grapevine cultivation that maybe could changes the plant microclimate and the ripening profile. The purpose of this work was to evaluate the POC influence on ripening evolution of grapes Moscato Giallo. The experiment was carried out in 2005/06 and 2006/07 seasons, in a vineyard covered with an impermeable plastic cloth (2.65 m x $160 \mu \mathrm{m})$, being left five rows without covering (control). Berries were collected (three replicates of 100 units for treatment) weekly in each area (POC and control). These berries were evaluated regarding to weight, diameter and must composition ( $\mathrm{pH},{ }^{\circ}$ Brix, titratable acidity, malic and tartaric content). At harvest it was characterized also the musts of covered and uncovered grapes ( ${ }^{\circ}$ Brix, reduced sugar, relative density, total acidity, tartaric and malic content, $\mathrm{pH}$ and must yield). POC modifies the microclimate in canopy and clusters influencing the grape ripening. Due to reduction of photosynthetically active radiation, that slows the sugar accumulation, the POC grapevines should be harvest after compared to conventional grapes.
\end{abstract}

Index terms: plasticulture, microclimate, ripening, management.

\section{INTRODUÇÃO}

A maturação adequada das uvas é de extrema importância para a qualidade dos vinhos. Neste período, muito da qualidade enológica é determinado, pois é quando ocorre a síntese, degradação e/ou a translocação de compostos desejáveis para as bagas, tais como: açúcares, terpenos, antocianinas, taninos, ácidos orgânicos, entre outros (Conde et al., 2007). Entretanto, no período de maturação, podem também ocorrer injúrias ocasionadas por pragas ou doenças, as quais poderão interferir na composição físicoquímica das bagas (Chavarria et al., 2007).

Na região da Serra Gaúcha, que é a principal região produtora de vinhos do País, ocorrem com frequência chuvas em excesso no período de maturação (Westphalen \& Maluf, 2000). Desta forma,

\footnotetext{
${ }^{1}$ (Trabalho 032-09). Recebido em: 20-01-2009. Aceito para publicação em: 23-06-2009.

${ }^{2}$ Eng. Agr ${ }^{\circ}$ Dr. Professor Fisiologia das Plantas Cultivadas, Universidade de Passo Fundo, CEP 99001-970, Passo Fundo-RS. e-mail: geraldochavarria@upf.br

${ }^{3}$ Eng. Agr ${ }^{\circ}$ Dr. Pesquisador Embrapa Uva e Vinho, CEP 95700-000, Bento Gonçalves-RS., e-mail: henrique@cnpuv.embrapa.br ${ }^{4}$ Eng. Agr ${ }^{\circ}$ M.Sc. Pesquisador Embrapa Uva e Vinho, CEP 95700-000, Bento Gonçalves-RS., e-mail: zanus@cnpuv.embrapa.br ${ }^{5}$ Eng. Agr ${ }^{\circ}$ Professor Dr. Departamento de Horticultura, Universidade Federal do Rio Grande do Sul, CEP 91540-000, Porto AlegreRS. e-mail: marodin@ufrgs.br

${ }^{6}$ Quím. Dr. Laboratorista Embrapa Uva e Vinho, CEP 95700-000, Bento Gonçalves-RS., e-mail: monica@cnpuv.embrapa.br ${ }^{7}$ Enólogo Bolsista DTI - Embrapa Uva e Vinho, CEP 95700-000, Bento Gonçalves-RS., e-mail: zorzan@cnpuv.embrapa.br. Bolsista $\mathrm{CNPq}$
} 
os produtores são obrigados a realizar colheitas antecipadas com objetivo de garantir as safras. Esta prática tem sido realizada com o intuito de evitar perdas ocasionadas por podridões dos frutos, porém resulta no comprometimento da qualidade enológica do mosto pela paralisação do processo de maturação (Tonietto \& Falcade, 2003).

Em função da modificação microclimática que as coberturas plásticas impermeáveis propiciam às linhas de cultivo, estas tornam-se uma alternativa viável na diminuição das podridões de cachos ocorridas no período de maturação, incrementando a qualidade e a produção, principalmente pela restrição da água livre sobre as folhas e cachos (Chavarria et al., 2007).

Contudo, sabe-se que, nas condições do cultivo protegido em questão, as temperaturas são mais elevadas e a radiação solar é restringida (Cardoso et al., 2008). Estes dois fatores são os elementos climáticos de maior relevância na síntese de compostos, levando em consideração sua influência nos metabolismos primário e secundário das plantas (Taiz \& Zeiger, 2004). Maiores níveis de exposição dos cachos à radiação solar estão relacionados a maiores acúmulos de sólidos solúveis totais (Morrison \& Noble, 1990), redução do pH (Toda et al., 1991), concentração de potássio (Smart et al., 1985), decréscimo de acidez total (Archer \& Strauss, 1989), acréscimo de teores de antocianinas e outros compostos fenólicos em variedades tintas (Beer et al., 2002).

Como o cultivo protegido é um sistema de produção bastante recente na obtenção de uvas destinadas a vinificação (Chavarria et al., 2008b), não são conhecidos os efeitos da alteração microclimática sobre a maturação das uvas. Desta forma, o presente trabalho teve por objetivo avaliar a influência da cobertura plástica impermeável sobre a maturação de uvas ‘Moscato Giallo’.

\section{MATERIAL E MÉTODOS}

O experimento foi conduzido nos ciclos de 2005/06 e 2006/07, nos vinhedos de uma vinícola localizada em Flores da Cunha - RS, distrito de Mato Perso (2906'S, 51 '20'O e altitude $541 \mathrm{~m}$ ). A cultivar empregada foi a 'Moscato Giallo' (clone VCR1), enxertada em porta-enxerto 'Kober 5BB' e com espaçamento de 3,0 x 0,9 m (3703 plantas.ha-1).

As plantas estavam conduzidas em " $Y$ " com fileiras de 35 metros na direção nordeste-sudoeste, com poda mista, deixando quatro varas de 6-8 gemas e oito esporões de duas gemas. $\mathrm{O}$ vinhedo foi dividido em duas partes. A primeira parte foi constituída por 12 fileiras cobertas na linha de cultivo com lonas plásticas trançadas de polipropileno transparentes, impermeabilizadas com polietileno de baixa densidade, com $160 \square \mathrm{m}$ de espessura e largura de 2,65 $\mathrm{m}$. Entre as fileiras, havia uma descontinuidade da cobertura com aproximadamente um metro de distância. Na segunda parte do vinhedo, mantiveram-se cinco fileiras descobertas, cujas linhas centrais foram consideradas como plantas-controle.

O microclima foi avaliado por medições de temperatura e umidade relativa do ar (psicrômetros de pares termoelétricos); velocidade do vento (anemômetro de conchas) e radiação fotossinteticamente ativa (400-700 nm, barras de 1,20 m equipadas com cinco células fotovoltaicas ligadas em série), na altura do dossel vegetativo. Todos os sensores da área experimental foram conectados a sistemas de aquisição de dados (CR10 e CR21X, Campbell ${ }^{\circledR}$ ). Ambos os sistemas foram programados para efetuar leituras a cada minuto e médias a cada 30 minutos.

A partir do início da maturação (estádio 81 - escala de Lorenz et al., 1995), foram feitas amostragens de uvas semanais. Em cada área, foram retiradas três repetições de 100 bagas da parte mediana do cacho em todos os quadrantes. As amostras foram conduzidas ao laboratório e esmagadas para extração do mosto, o qual foi centrifugado e, imediatamente, submetido às análises.

Na colheita, também foram colhidas aleatoriamente, em 10 plantas de cada área (coberta e descoberta), três amostras de $28 \mathrm{~kg}$ de uva na safra de 2006 (02-03-06) e na de 2007, em dois períodos (12-02-07 e 22-02-07). Na safra de 2007, foram realizadas duas colheitas, pois no primeiro ano de experimento já haviam sido observadas diferenças no comportamento da maturação em função do uso da cobertura plástica. Desta maneira, optou-se pela na realização de colheitas obedecendo ao ponto de colheita em cada sistema de cultivo (teor de açúcar e acidez total titulável do mosto).

As amostras de uva foram desengaçadas, esmagadas, prensadas e calculado o rendimento de mosto, e, após, retirada uma alíquota de $100 \mathrm{~mL}$ em cada repetição para a realização das análises no mesmo momento ( ${ }^{\circ}$ Brix, açúcares redutores, densidade, acidez total titulável, ácidos tartárico e málico e $\mathrm{pH})$.

As amostras semanais e os mostos da colheita de cada tratamento foram analisados nos Laboratórios de Enoquímica e de Instrumentação da Embrapa Uva e Vinho. O teor de sólidos solúveis totais ( ${ }^{\circ}$ Brix) foi obtido através da leitura em um refratômetro de bancada com correção automática de temperatura (marca American Optical; modelo 10460). A densidade foi determinada através de um densímetro digital 
(marca Anton Paar; modelo DMA-45). Os açúcares redutores foram avaliados segundo método de Meyer \& Leygue-Alba (1991). A acidez titulável (meq.L-1 $\left.{ }^{-1}\right)$ foi determinada por titulação do mosto com $\mathrm{NaOH}$ $0,1 \mathrm{~N}$, utilizando azul de bromotimol como indicador ( $\mathrm{pH} 8,2) . \mathrm{O} \mathrm{pH}$ foi medido com um potenciômetro digital (marca Corning; modelo 125), equipado com eletrodo de vidro e calibrado com soluções-padrão de pH 3,0 e pH 4,0 (Ribéreau-Gayon et al., 1976).

Os ácidos tartárico e málico foram analisados por cromatografia líquida de alta performance (CLAE), utilizando um aparelho equipado com um injetor Rheodyne de $20 \mathrm{~mL}$ de volume, um detector UV/VIS e uma coluna VARIAN MCH-NCAP-5 (Auguste, 1979).

As variáveis de contéudo de ácido málico e tartárico, pH, sólidos solúveis, acidez total titulável, açúcares redutores e densidade foram submetidas à análise da variância, e as médias, comparadas pelo teste de Tukey, a 5\% de probabilidade de erro.

\section{RESULTADOS E DISCUSSÃO}

No vinhedo sob cobertura plástica, observouse uma diferenciação microclimática em relação à área sem cobertura. De forma geral, ao longo do ciclo, destaca-se que a cobertura aumentou a temperatura, sobretudo as máximas, e reduziu drasticamente a incidência de radiação fotossinteticamente ativa no dossel vegetativo (-37\%) e nos cachos (-40\%), assim como a velocidade do vento $(-90,4 \%)$. Na avaliação do microclima durante o período de maturação (mudança de cor das bagas até a colheita), também foi observado o mesmo que ao longo do ciclo como um todo, apresentando um incremento nas temperaturas máximas em relação ao descoberto, aumentando com isso as temperaturas médias (Figura 1).

A radiação fotossinteticamente ativa (RFA) foi reduzida ao nível dos cachos pelo uso da cobertura plástica. Contudo, nestas condições de cultivo, comparativamente ao primeiro ciclo, o segundo ciclo apresentou maior dispobibilidade de radiação para os cachos (Figura 1). Isto se deveu ao fato de que, no ciclo de 2006/07, foi realizada uma desfolha (retirada de folhas próximo ao período de maturação) mais severa, comparativamente ao ciclo anterior, o que promoveu maior luminosidade no nível dos cachos das plantas cobertas. Deve ser salientada a importância do procedimento de desfolha associado ao cultivo protegido de videiras, pois este reduz o efeito de sombreamento proporcionado pela cobertura plástica sobre o vinhedo.

No primeiro ciclo avaliado (2005/06), não foi observado efeito significativo da cobertura plástica ao longo da evolução da maturação, em relação aos níveis de sólidos solúveis (SS), pH e acidez total titulável (ATT). No final do ciclo (13-2), o pH das uvas do cultivo coberto foi significantemente inferior ao observado na área descoberta (Figura 2). No ciclo de 2006/07, o pH do cultivo coberto também foi significantemente inferior nas três últimas avaliações (24-01, 31-01 e 07-02) (Figura 3). Também se observou diferença independentemente dos tratamento, na ATT, entre os ciclos estudos. No primeiro ciclo, as uvas apresentaram níveis de ATT superiores ao mesmo período de avaliação no ano seguinte, possivelmente relacionado a temperaturas mais elevadas ocorridas no ciclo de 2006/07 (Figuras 2 e 3). AATT, que é influenciada diretamente pelo $\mathrm{pH}$ (Manfroi et al., 2006), apresentou decréscimo ao longo do processo de maturação nos dois tratamentos, contudo não foi afetada pela utilização da cobertura plástica nos dois ciclos avaliados, com exceção da avaliação do dia 10-01, no segundo ciclo, quando a ATT foi significativamente menor sob cobertura. Embora, de forma geral, não tenham sido observadas diferenças significativas, pôde-se observar que a ATT, nos dois ciclos de estudos, no início da maturação, apresentou menores valores na área coberta (Figuras 2 e 3), indicando, possivelmente, um adiantamento no processo de maturação, conforme observado em avaliações fenológicas por Chavarria et al., 2008a.

Corroborando os dados observados de ATT, as concentrações de SS apresentaram patamares iniciais distintos entre os dois anos estudados, independentemente dos tratamentos realizados, apresentando SS inferiores no início de avaliação do ciclo de 2005/06, comparativamente ao ciclo de 2006/07 (Figuras 2 e 3). Associado aos altos níveis de ATT, isto indica que as uvas do ciclo de 2006/07 iniciaram a maturação mais tardiamente. Comparando os tratamentos (coberto e descoberto), no ciclo de 2006/07, as uvas não apresentaram diferenças significativas, embora tenha sido observada tendência de maiores concentrações nas fases iniciais de maturação na área coberta (Figura 2). Já, no segundo ciclo (2006/07), foram encontradas diferenças significativas nas duas primeiras avaliações (03 e 10 de janeiro), tendo a área coberta concentrações superiores de SS (Figura 3). A cobertura plástica propicia um ambiente com temperaturas mais elevadas, o que facilita a antecipação da brotação e do desenvolvimento das plantas, proporcionando aumento adiantado dos níveis de SS, quando feita a comparação com a área coberta. Chavarria et al. (2008a) demonstraram tais efeitos estudando a fenologia da cultivar Moscato Giallo, a qual antecipou seu desenvolvimento fenológico desde a poda até a mudança de cor das bagas. Além 
disso, os autores observaram que, com a redução da RFA, houve prolongamento no período de maturação das uvas, sendo, desta forma, observados dois efeitos na fenologia das videiras.

O conteúdo de ácido tartárico das bagas das uvas sob cobertura plástica foi significativamente superior em três avaliações realizadas (18-01, 12-02 e 22-02) (Figura 4A). Na análise do mosto, diferenças significativas só foram constatadas na avaliação da segunda colheita da safra de 2007, quando a área coberta apresentou quantidades superiores à descoberta (Tabela 1). Este ácido tem sua biossíntese iniciada com o ácido ascórbico, o qual é clivado e convertido em ácido tartárico nas folhas (Conde et al., 2007). Sabe-se também que se trata de um ácido orgânico mais estável se comparado ao málico (Conde et al., 2007).

O ácido málico teve valores significativamente inferiores no tratamento da área coberta em três avaliações, no início da maturação (05-01, 11-01 e 25-01) (Figura 4B), com uma tendência a menores concentrações no mosto, apresentando 2,7 e 3,1 g.L $L^{-1}$ na safra de 2006 e, 2,80 e 3,17 g.L - $^{-1}$ na segunda colheita de 2007, nos cultivos coberto e descoberto, respectivamente (Tabela 1). Cabe também ressaltar que, na safra de 2007, o conteúdo de ácido málico presente nas uvas sob cobertura plástica diminuiu 25,3\% de uma colheita para a outra, ou seja, em um intervalo de 10 dias (Tabela 1). Este comportamento pode estar relacionado a uma degradação de ácidos orgânicos ocasionada por temperaturas mais elevadas sob cobertura plástica. Alguns trabalhos demonstram a influência da temperatura sobre a síntese dos ácidos orgânicos (Lakso \& Kliewer, 1975). Sabe-se que a enzima málica que degrada o ácido málico aumenta sua atividade com o incremento da temperatura até $46^{\circ} \mathrm{C}$, o que denota uma alta estabilidade térmica desta enzima, ao passo que o fosfoenolpiruvato, que é precursor do ácido málico, é altamente afetado por temperaturas elevadas $\left(38^{\circ} \mathrm{C}\right)$ (Conde et al., 2007). Estas duas informações indicam que o decréscimo do ácido málico durante a maturação das uvas é resultado da redução da síntese do ácido málico em combinação com uma aceleração catabólica. Desta maneira, devido ao incremento das temperaturas que a cobertura plástica propicia, o conteúdo de ácido málico nas bagas é afetado (Figura 4).

Embora na área coberta tenham sido observadas menores concentrações de ácido málico, o pH foi significativamente inferior nestas condições. Isto evidencia que o pH não está somente na dependência dos ácidos orgânicos, mas também da salificação dos ácidos e da presença de cátions de potássio (Manfroi et al., 2004). Ribéreau-Gayon (1959) estudou o efeito do sombreamento na maturação de cachos da cultivar Cabernet Sauvignon e observou aumento de 5-9\% na ATT do mosto comparado a cachos completamente expostos à radiação solar.

A relação entre o ácido tartárico e o málico aumentou desde o início da maturação até a colheita (Figura 4C), sendo que, na maioria das avaliações, os valores foram significativamente maiores nas uvas da área coberta. Este fato deveu-se às maiores quantidades de ácido tartárico e à menor de ácido málico, proporcionados pela cobertura plástica.

Na safra de 2006 e na segunda colheita de 2007, foram observadas diferenças significativas em relação ao rendimento do mosto durante o processamento (prensagem), sendo este superior em 7 e $8 \%$ nas uvas provenientes da área coberta, nas respectivas safras (Tabela 1). Este maior rendimento, possivelmente, tenha relação direta com a maior massa individual e o conteúdo de água das bagas sob cobertura plástica, como o observado na safra de 2006.

A análise físico-química do mosto na colheita, na safra de 2006, indicou que a cobertura plástica impermeável propiciou menor densidade e menor quantidade de açúcares redutores (Tabela 1). Estes resultados reforçam a ideia de que as uvas deste tratamento não alcançaram o mesmo estádio de maturação das uvas do cultivo descoberto, no momento da colheita (Tabela 1). Este atraso na maturação deve-se à interferência que a cobertura exerce sobre este processo fisiológico, estendendo o período de maturação a partir da mudança de cor das bagas até a colheita, possivelmente pela diminuição da radiação solar. Isto implica a necessidade de atrasar a data de colheita das uvas cultivadas sob cobertura plástica, a fim de propiciar a máxima maturação fisiológica e tecnológica dos frutos. Este procedimento é possível neste sistema de cultivo devido à garantia fitossanitária que a cobertura plástica propicia para o vinhedo (Chavarria et al., 2007).

Na primeira colheita da safra de 2007, o mosto da área coberta apresentou-se distinto do cultivo descoberto somente em relação ao maior nível de ATT (Tabela 1). Contudo, na segunda colheita, este mosto apresentou maior concentração de ácido tartárico, seguindo a tendência da primeira colheita, embora esta não tenha sido significativa (Figura 3). Portanto, o atraso da colheita nesta safra reduziu o $\mathrm{pH}$ do mosto da área coberta se comparada ao tratamento sem cobertura plástica (Tabela 1).

Considerando, em conjunto, o acúmulo de açúcares e a degradação dos ácidos orgânicos no período de maturação das uvas, pode-se sugerir que as taxas de incremento de açúcar nas bagas, neste estádio 
fenológico, sejam menores que as de degradação de ácidos orgânicos, já que os níveis dos ácidos no mosto tiveram comportamento diferenciado, se comparados ao cultivo descoberto (Tabela 1). A maior degradação do ácido málico pelo aumento da temperatura pode justificar a similaridade em ATT das uvas, por acasião da colheita, apesar das diferenças de acúmulo de açúcares (Tabela 1). Contudo, o acúmulo de açúcar tem influência não só da temperatura, mas também da radiação solar (Mullins et al., 1992). E como a cobertura restringe em até $56 \%$ a radiação no nível dos cachos (Chavarria et al., 2009), isto pode justificar o decréscimo na taxa de incremento de açúcar ao longo da maturação. Este efeito pode ser mais importante quando o período de maturação das uvas coincide com condições climáticas de menor insolação, como ocorreu na safra de 2006.

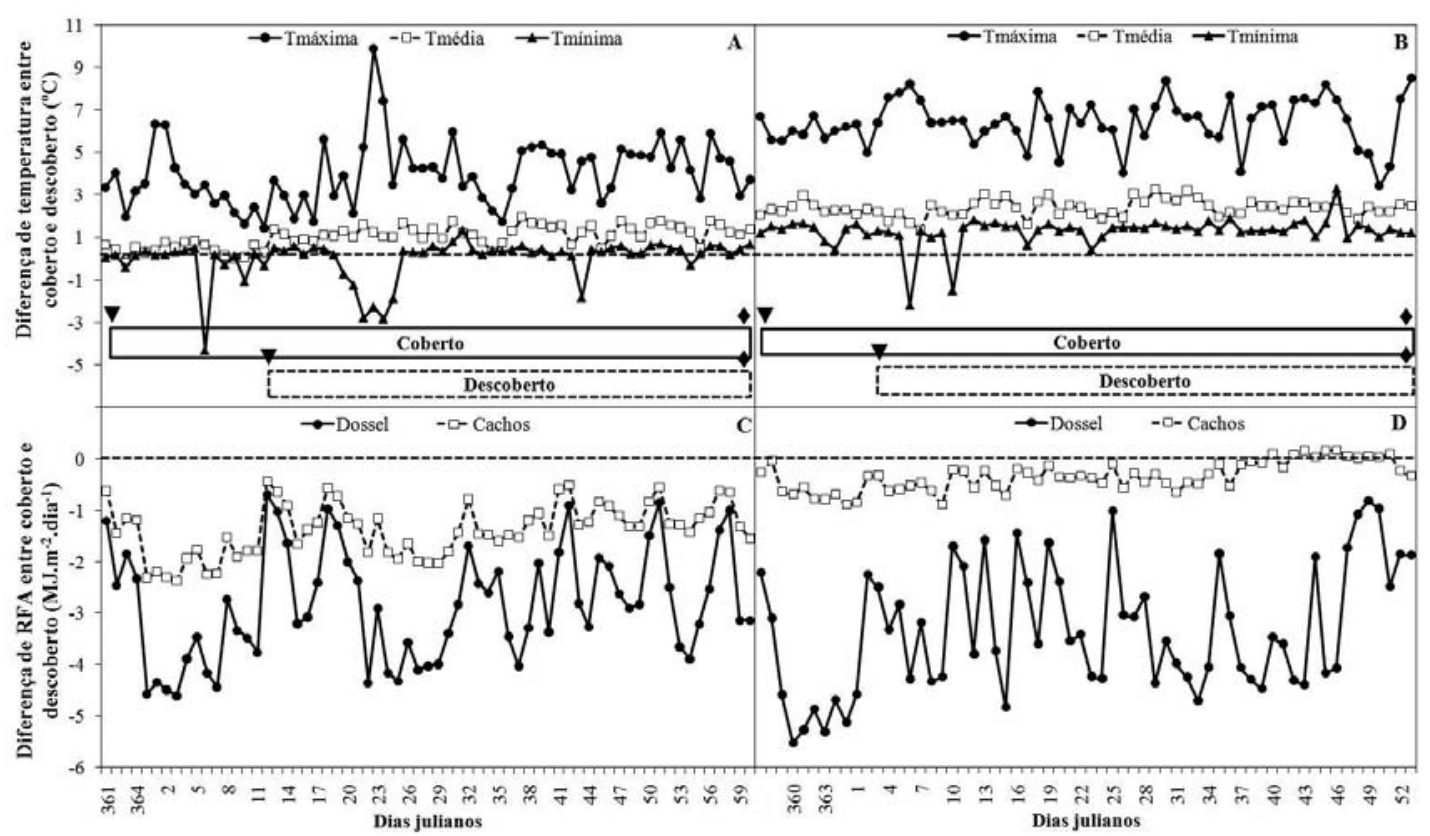

FIGURA 1 - Diferença relativa entre as temperaturas máxima, média e mínima (A - ciclo 2005/06 e B 2006/07) e a radiação incidente no dossel vegetativo e nos cachos (C - ciclo 2005/06 e D 2006/07), no período de mudança de cor até a colheita em vinhedo da cultivar Moscato Giallo com (coberto) e sem (descoberto) cobertura plástica. As barras horizontais representam o período de início ao fim de maturação das uvas cobertas e descobertas. 


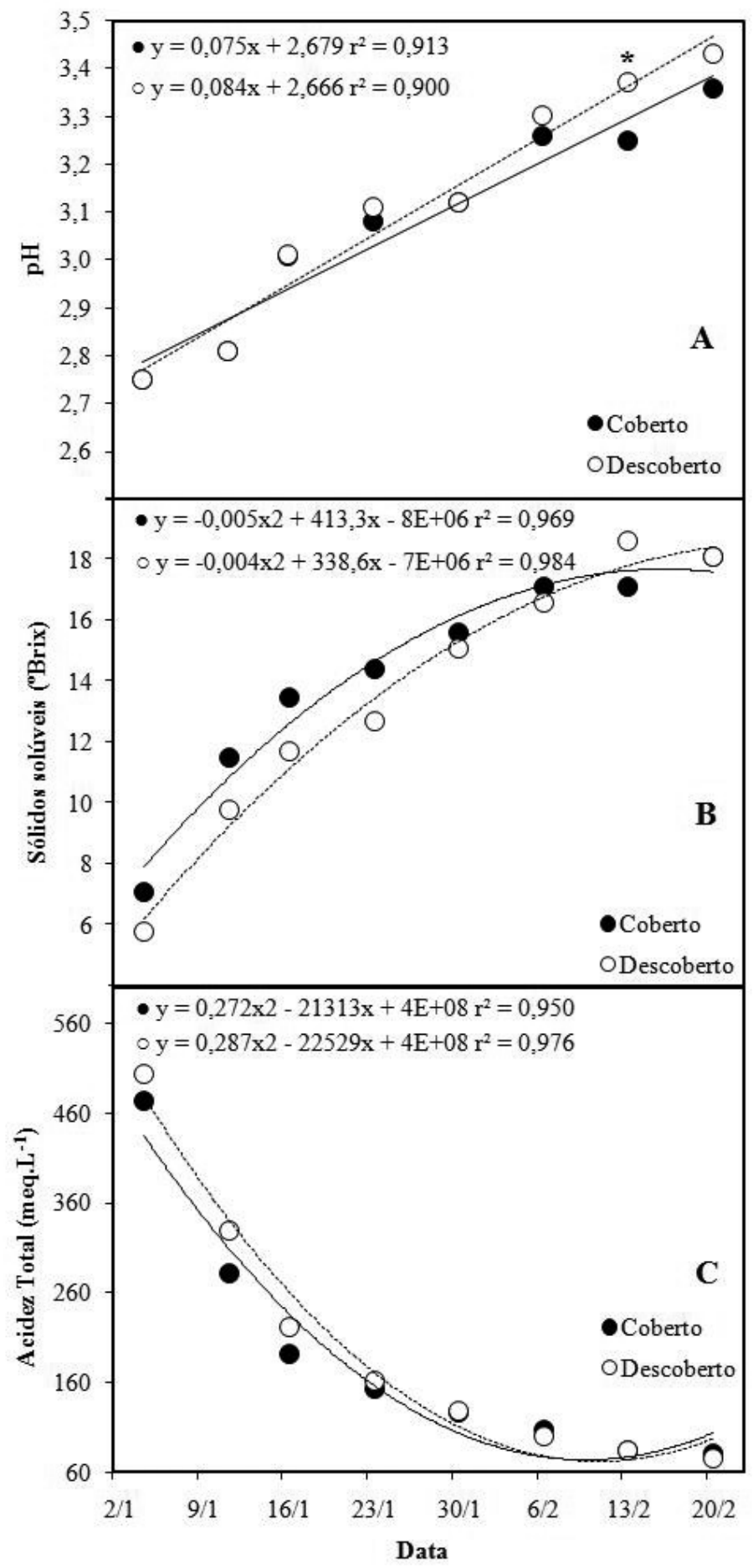

FIGURA 2- Curva de maturação (pH - A, sólidos solúveis - B e acidez total - C) de uvas cv. Moscato Giallo cultivada com (coberto) e sem (descoberto) cobertura plástica, no ciclo de 2005/06. A presença de asterísco representa diferença ao nível de 5\% de probabilidade de erro, de acordo com o teste de Tukey. Regressão em linha cheia representa o cultivo coberto, e a tracejada, o descoberto. 


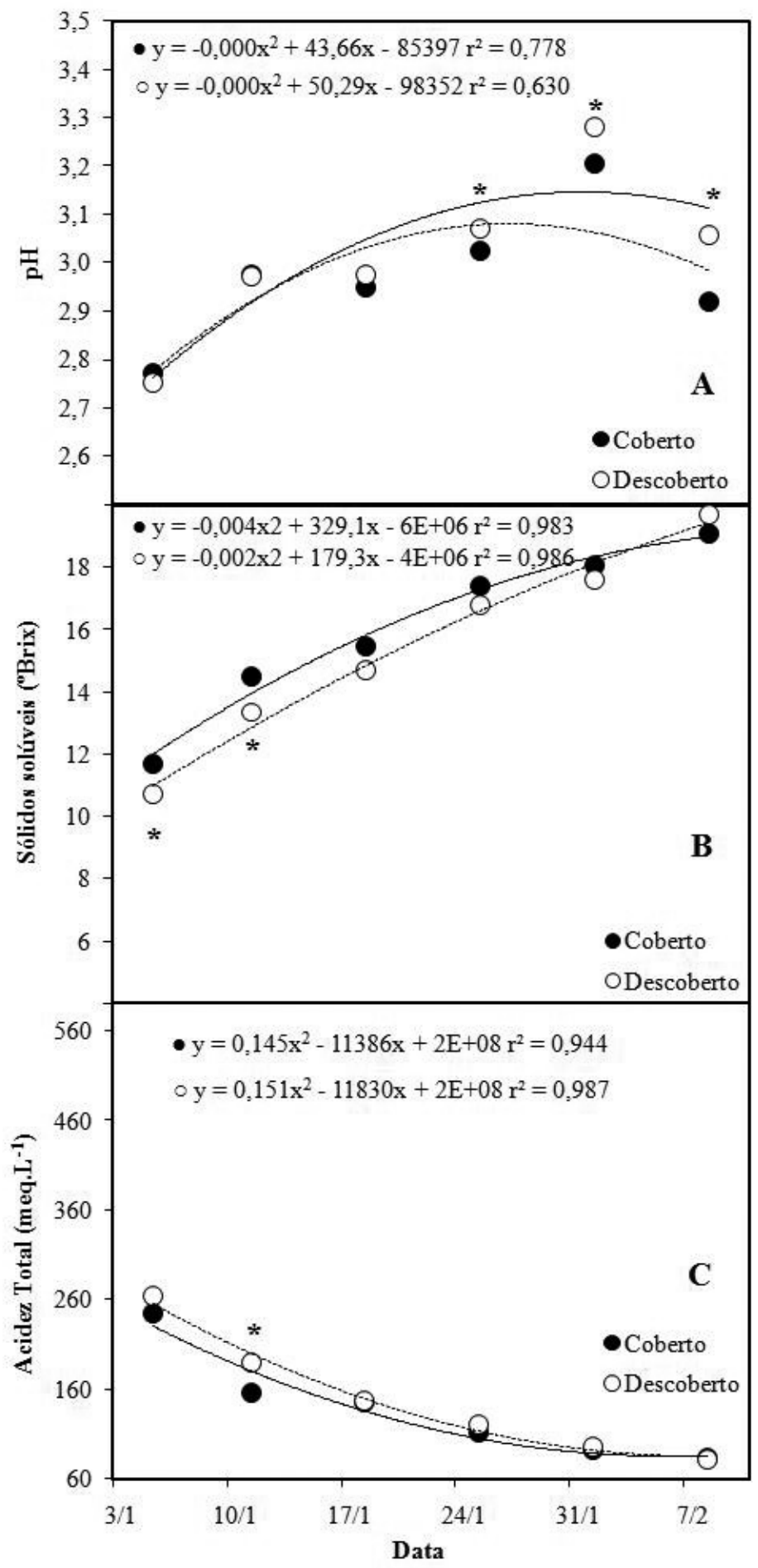

FIGURA 3- Curva de maturação (pH - A, sólidos solúveis - B e acidez total - C) de uvas cv. Moscato Giallo cultivada com (coberto) e sem (descoberto) cobertura plástica, no ciclo de 2006/07. A presença de asterísco representa diferença ao nível de 5\% de probabilidade de erro, de acordo com o teste de Tukey. Regressão em linha cheia representa o cultivo coberto, e a tracejada, o descoberto. 


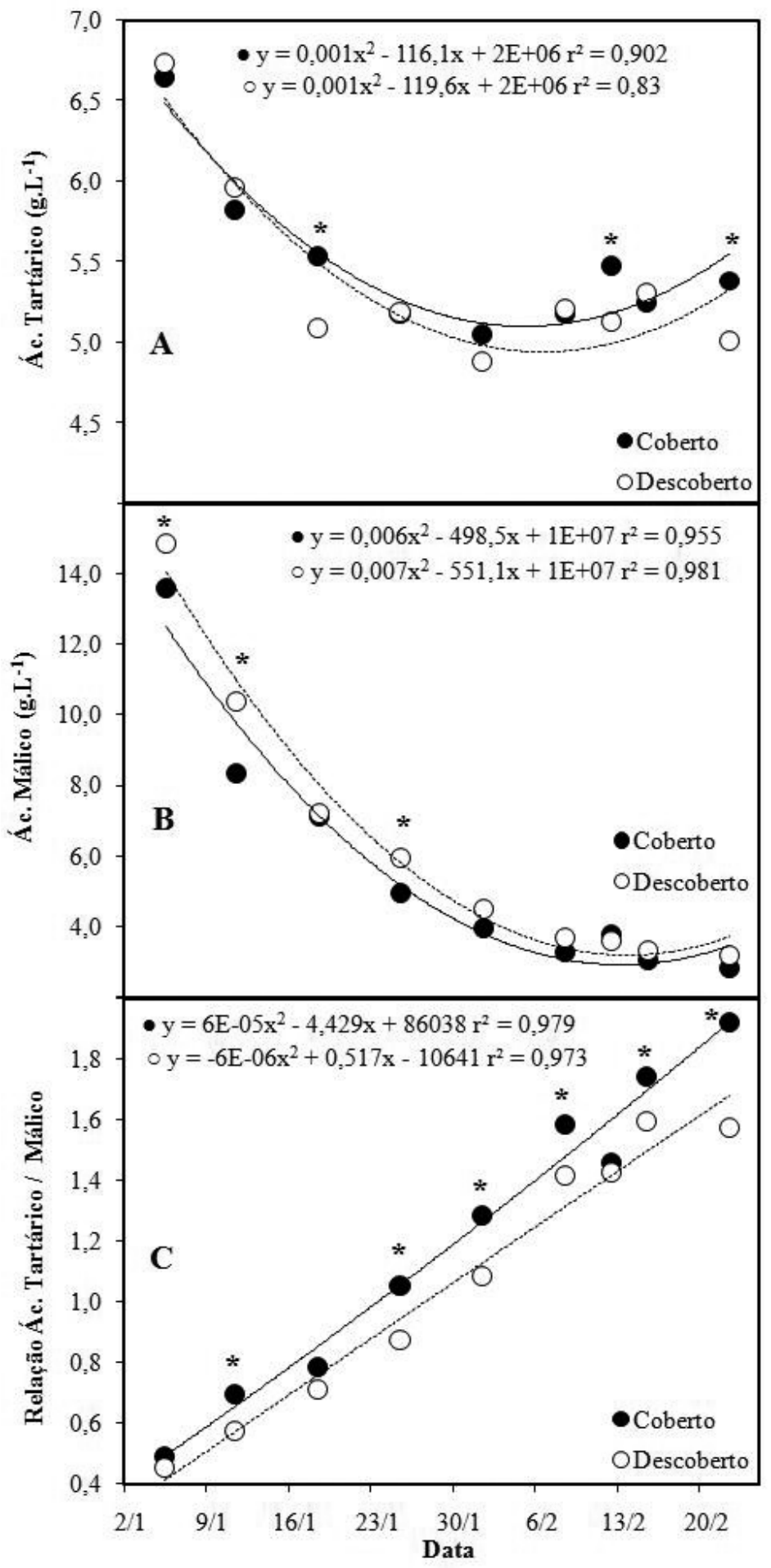

FIGURA 4- Conteúdo de ácidos tartárico (A) e málico (B) e sua respectiva relação (C) ao longo da maturação de uvas cv. Moscato Giallo cultivada com (coberto) e sem (descoberto) cobertura plástica, no ciclo de 2006/07. Flores da Cunha-RS. A presença de asterísco representa diferença ao nível de 5\% de probabilidade de erro, de acordo com o teste de Tukey. Regressão em linha cheia representa o cultivo, coberto, e a tracejada, o descoberto. 
TABELA 1 - Composição química de mostos na colheita da cultivar Moscato Giallo com (coberto) e sem (descoberto) cobertura plástica.

\begin{tabular}{|c|c|c|c|c|c|c|}
\hline \multirow[t]{2}{*}{ Análises } & \multicolumn{2}{|c|}{ Safra 2006} & \multicolumn{2}{|c|}{$\begin{array}{c}\text { Safra } 2007 \\
\left(1^{\circ} \text { Colheita }\right)^{* *}\end{array}$} & \multicolumn{2}{|c|}{$\begin{array}{c}\text { Safra } 2007 \\
\left(2^{\circ} \text { Colheita) }\right)^{* *}\end{array}$} \\
\hline & Coberto & Descoberto & Coberto & Descoberto & Coberto & Descoberto \\
\hline Sólidos solúveis ( $\left.{ }^{\circ} \mathrm{Brix}\right)$ & $17,5 b b^{*}$ & $19,0 \mathrm{aA}$ & $18,4 \mathrm{aAB}$ & $19,1 \mathrm{aA}$ & $19,1 \mathrm{aA}$ & $19,1 \mathrm{aA}$ \\
\hline Açúcares redutores (g.L ${ }^{-1}$ ) & $182,0 \mathrm{bA}$ & $197,3 \mathrm{aA}$ & $171,7 \mathrm{aA}$ & $179,2 \mathrm{aB}$ & $179,3 \mathrm{aA}$ & $179,5 \mathrm{aA}$ \\
\hline Densidade relativa & $1,075 \mathrm{bA}$ & $1,082 \mathrm{aB}$ & $1,076 \mathrm{aA}$ & 1,079aB & $1,079 \mathrm{bA}$ & $1,320 \mathrm{aA}$ \\
\hline Acidez total titulável (meq.L $\mathrm{L}^{-1}$ ) & $74,0 \mathrm{aB}$ & $76,0 \mathrm{aA}$ & 89,3aA & $77,3 \mathrm{bA}$ & 73,3аB & $74,7 \mathrm{aA}$ \\
\hline Ác. Tartárico (g.L -1) $^{-1}$ & $5,1 \mathrm{aA}$ & $4,9 \mathrm{aA}$ & $5,47 a A$ & $5,12 \mathrm{aA}$ & 5,38aA & $5,00 \mathrm{bA}$ \\
\hline Ác. Málico (g.L ${ }^{-1}$ ) & $2,7 \mathrm{aB}$ & $3,1 \mathrm{aB}$ & $3,75 a A$ & 3,59aA & $2,80 \mathrm{aB}$ & $3,17 \mathrm{aAB}$ \\
\hline $\mathrm{pH}$ & $3,2 \mathrm{bB}$ & $3,5 \mathrm{aB}$ & 3,33aA & 3,39aC & 3,39bA & $3,58 \mathrm{aA}$ \\
\hline Rendimento em Mosto (\%) & $48,6 \mathrm{aA}$ & $45,1 \mathrm{bAB}$ & $42,13 \mathrm{aB}$ & $40,36 \mathrm{aB}$ & $44,87 \mathrm{aA}$ & $42,04 \mathrm{bB}$ \\
\hline
\end{tabular}

*médias (representam a média de três repetições) na linha seguidas pela mesma letra minúscula (entre os tratamentos coberto e descoberto) ou maiúscula (entre as safras em cada tratamento) não diferem entre si, de acordo com teste Tukey, ao nível de 5\% de probabilidade de erro.**diferença de dez dias entre a primeira e a segunda colheita da safra de 2007.

\section{CONCLUSÕES}

1-A despeito de uma importante interferência no microclima do dossel vegetativo e nos cachos, a cobertura plástica influencia na maturação das uvas.

2-Em função da diminuição da radiação fotossinteticamente ativa, que retarda o acúmulo de açúcares, as uvas sob cobertura plástica devem ser colhidas posteriormente àquelas do cultivo convencional.

\section{REFERÊNCIAS}

ARCHER, E.; STRAUSS, H.C. Effect of shading on the performance of Vitis vinifera L. cv. Cabernet Sauvignon. South African Journal of Enology and Viticulture, Dennesig, v.10, p.74-77, 1989.

AUGUSTE, M.H. Application de la chromatographie en phase liquide à haute pression à l'analyse des moûts et des vins. 1979. 35f. Tese (Doutorado em Enologia) - Université de Bordeaux II, Talence, 1979.

BEER, D.; JOUBERT, E.; GELDERBLOM, W.C.A.; MANLEY, M. Phenolic compounds: a review of their possible role as in vivo antioxidants of wine. South African Journal of Enology and Viticulture, Dennesig, v.23, p.48-61, 2002.
CARDOSO, L.S.; BERGAMASCHI, H.; COMIRAN, F.; CHAVARRIA, G.A.B.M.; DALMAGO, G.A.; SANTOS, H.P.; MANDELLI, F. Alterações micrometeorológicas em vinhedos pelo uso de coberturas de plástico. Pesquisa Agropecuária Brasileira, Brasília, v.43, p.441-447, 2008.

CHAVARRIA, G. Ecofisiologia e fitotecnia do cultivo protegido de videiras cv. Moscato Giallo (Vitis vinifera L.) 2008. 136f. Tese (Doutorado em Fitotecnia) - Faculdade de Agronomia, Universidade Federal do Rio Grande do Sul, Porto Alegre, 2008.

CHAVARRIA, G.; SANTOS, H.P.; SÔNEGO, O.R.; MARODIN, A.B.; BERGAMASCHI, H.; CARDOSO, L.S. Incidência de doenças e necessidade de controle em cultivo protegido de videira. Revista Brasileira de Fruticultura, Jaboticabal, v.29, n.3, p.477-482, 2007.

CONDE, C.; SILVA, P.; FONTES, N.; DIAS, A.C.P.; TAVARES, R.M.; SOUSA, M.J.; AGASSE, A.; DELROT, S.; GERÓS, H. Biochemical changes throughout grape berry development and fruit and wine quality. Food, Berlin, v.1, n.1, p.1-22, 2007.

CHAVARRIA, G.; SANTOS, H.P.; MANDELLI, F.; GILMAR, A.B.M.; BERGAMASCHI, H.; CARDOSO, L.S. Caracterização fenológica e requerimento térmico da cultivar Moscato Giallo sob cobertura plástica. Revista Brasileira de Fruticultura, Jaboticabal, v.31, p.119-126, 2008a. 
CHAVARRIA, G.; SANTOS, H.P.; MANDELLI, F.; MARODIN, G.A.B.; BERGAMASCHI, H.; CARDOSO, L.S. Potencial produtivo de videiras cultivadas sob cobertura de plástico. Pesquisa Agropecuária Brasileira, Brasília, v. 44, p. 141147, 2009.

CHAVARRIA, G.; SANTOS, H.P.; FELIPEETO, J.; MARODIN, G.A.B.; BERGAMASCHI, H.; CARDOSO, L.S.; BELLO FIALHO, F. Relações hídricas e trocas gasosas em vinhedo sob cobertura plástica. Revista Brasileira de Fruticultura, Jaboticabal, v.30, p.1022-1029, 2008b.

LAKSO, A.N.; KLIEWER, W.M. The influence of temperature on malic acid metabolism in grape berries I. Enzyme responses. Plant Physiology, Bethesda, v.56, p.370-372, 1975.

LORENZ, D.H.; EICHORN, K.W.; BLEHOLDER, H., KLOSE, R.; MEIER, U.; WEBER, E. Phenological growth stages of grapevine (Vitis vinifera L.) - Codes and descriptions according to the extended BBCH scale. Australian Journal of Grape and Wine Research, Glen Usmond, v.1, p.100-103, 1995.

MANFROI, L.; MIELE, A.; RIZZON, L.A.; BARRADAS, C.I.N.; SOUZA, P.V.D. Evolução da maturação da uva Cabernet Franc conduzida no sistema lira aberta. Ciência Agrotécnica, Lavras, v.28, p.306-313, 2004.

MEYER, C.R.; LEYGUE-ALBA, N.M.R. Manual de métodos analíticos enológicos. Caxias do Sul: UCS, 1991. 51p.

MORRISON, J.C.; NOBLE, A.C. The effects of leaf and cluster shading on the composition of Cabernet Sauvignon grapes and on fruit and wine sensory properties. American Journal Enology and Viticulture, Davis, v.41, p.193-200, 1990.
MULLINS M.G. et al. Biology of the grapevine. New York: Cambridge University Press, 1992. 239p.

RIBÉREAU-GAYON, P. Recherché sur les anthocyannes des vegetaux : application au genre vitis. Paris: Librairie Générale Enseignement, 1959. 114p.

RIBÉREAU-GAYON, J.; PEYNAUD, E.; RIBÉREAU-GAYON, P.; SUDRAUD, P. Traité d'oenologie: sciences et techniques de vin. Paris: Dunod, 1976. v.1, 671p.

SMART, R.E. Principles of grapevine canopy microclimate manipulation with implications for yield and quality. American Journal of Enology and Viticulture, Davis, v.36, p.230-239, 1985.

TAIZ, L.; ZEIGER, E. Fisiologia Vegetal. 3.ed. Porto Alegre: Artmed, 2004.

TODA, F. M. de; SANCHA, J. C.; LLOP, E. Estudio comparado del microclima luminoso en los sistemas de conducción en vaso y espaldera en Rioja. Rivista di Viticoltura e di Enologia, Conegliano, v.44, n.4, p.149-156, 1991.

TONIETTO, J.; FACALDE, I. Regiões vitivinícolas brasileiras: uvas para processamento. Bento Gonçalves: Uva e Vinho, Brasília: Embrapa Informação Tecnológica, 2003. 134p. (Frutas do Brasil, 34).

WESTPHALEN, S.L.; MALUF, J.R.T. Caracterização das áreas bioclimáticas para o cultivo de Vitis vinifera L. nas regiões da Serra do Noroeste e Planalto do Estado do Rio Grande do Sul. Brasília: Embrapa Comunicação para Transferência de Tecnologia, Bento Gonçalves: Embrapa Uva e Vinho, 2000. 99p. 